\title{
Biografía
}

\section{“Dr. Rafael Angel Calderón Guardia: el médico"}

La faceta del doctor Rafael Ángel Calderón Guardia en su calidad de médico sin lugar a dudas influyó en su obra como gobernante, dada su vocación humanista.

Es casi imposible separar al profesional del hombre y al hombre del gobernante, más aún cuando como hombre y estadista alcanzó límites muy por encima del promedio, pero su obra, su ejemplo y su legado como médico, son realmente impresionantes.

El doctor Calderón Guardia nació en la ciudad de San José el 10 de marzo de 1900, asistió a la escuela Buenaventura Corrales y posteriormente al Colegio Seminario, donde siempre se destacó como un estudiante ejemplar. Su vocación por ayudar a sus semejantes se manifestó muy temprano en su vida, posiblemente alimentada por el ejemplo de su padre, el doctor Rafael Calderón Muñoz, a quien desde joven acompañaba para atender en sus casas a personas muy humildes, a las que les resultaba imposible recurrir a un médico cuando estaban enfermos, porque en aquellos tiempos existían pocos hospitales y las consultas médicas privadas resultaban muy onerosas.

Siguiendo los pasos de su padre, el doctor Calderón Guardia estudió en Bélgica, pero, a diferencia de él que estudió en la Universidad Católica de Lovaina, se graduó de médico en la Universidad Libre en Bruselas. A su regreso a Costa Rica se incorporó al Colegio de Médicos y Cirujanos el 8 de noviembre de 1927 y desde un inicio se identificó con las necesidades de los más pobres.

El doctor Calderón Guardia llegó a ser Presidente de la República el 8 de mayo de 1940 y forma parte de los pocos médicos que han tenido el honor de ocupar ese puesto.

Su capacidad y entrega, así como su habilidad como cirujano y sobre todo su claro criterio clínico, lo hicieron merecedor del reconocimiento de sus pacientes y colegas, quienes lo llevaron a ocupar la Presidencia del Colegio de Médicos y Cirujanos. Fue nombrado Jefe de Cirugía de Hospital San Juan de Dios, donde ejerció su profesión por varios años.

Un hecho impresionante, que habla de su pasión por la medicina y de su insaciable búsqueda del conocimiento, fue que una vez terminadas sus funciones como Presidente de la República, viajó a Nueva York para realizar estudios sobre cirugía de cáncer con el doctor George T. Pack, renombrado oncologo estadounidense. Su interés por esa patología no era nuevo, durante su gobierno había creado por decreto el

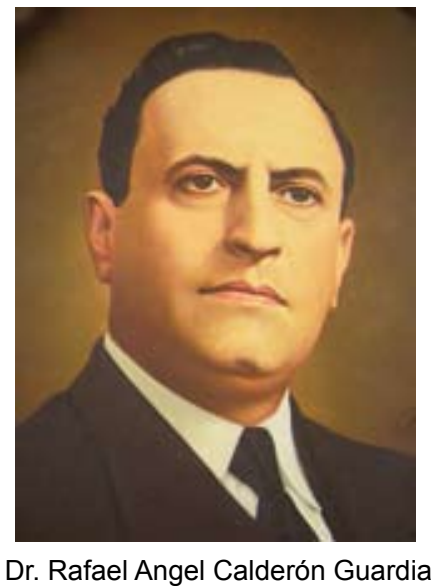

Instituto del Cáncer, con el fin de que se realizaran investigaciones en esa rama en nuestro país.

Su brillante carrera como médico, sin embargo, no fue obstáculo para que en una de las acciones más vergonzosas del Cuerpo Médico Nacional, se le expulsara del Colegio de Médicos por razones políticas el 4 de agosto de 1948. Este acto, acompañado de una suspensión a perpetuidad del ejercicio de la medicina y de la cirugía en el territorio nacional, fue sin duda un hecho denigrante.

No fue sino hasta el 23 de marzo de 1956 que, a petición expresa de cientos de médicos, el Presidente del Colegio, doctor Rodrigo Cordero Zúñiga, convocó a una sesión del Colegio en la que se levantó la sanción impuesta a él y a otros médicos, y a todos se les reincorporó de nuevo como miembros activos del colegio con todos sus derechos. Sin embargo, una mancha de esta magnitud no fue fácil de borrar $\mathrm{y}$, en la historia del Colegio de Médicos de Costa Rica permanecerá siempre la huella indeleble de este ignominioso acto en contra de varios de los más insignes galenos de nuestro país.

El doctor Calderón sentía verdadero amor por el prójimo, lo que lo llevó a hacer de su profesión un apostolado, sentimiento que compartía con su padre. Ambos tuvieron gran sensibilidad social, un profundo conocimiento científico y una moral a toda prueba, requisitos fundamentales para ser buenos médicos. El doctor Calderón Guardia poseía estas virtudes y más. Era un hombre elegante, con una educación exquisita, que mostraba igual respeto por un dignatario que por un humilde campesino. Todos reconocían en él a un excelente médico y a un caballero intachable. 
Cientos de familiares y amigos dan fe de su calidad humana, de su bondad y de sus conocimientos. Algunos de estos testimonios fueron recopilados para su publicación dentro del libro "Estadista, médico y hombre". Hasta la fecha, muchos recuerdan con profundo agradecimiento como el doctor Calderón, aun en el ejercicio de la Presidencia de la República, atendía el llamado de sus pacientes, visitándolos en sus hogares. Hijos y nietos de familias humildes cuentan cómo, no solo no les cobraba la consulta, sino que con frecuencia les compraba las medicinas o les dejaba discretamente la plata bajo la almohada para que pudieran adquirirlas. En otras ocasiones mandaba juguetes para los niños o cubría alguna necesidad apremiante de la familia.

El costo de una consulta en los años 30 era de 3 colones, y podemos observar en sus recetarios que tenía por costumbre recomendar o dirigir a sus pacientes a la Botica Vargas, pues ahí mantenía una cuenta abierta en la que le apuntaban el costo de los medicamentos llevados por los pacientes que no podían pagar. El recetario mostraba sus números telefónicos: el 2812 de su oficina y el 3200 de su casa. Además tenía impresa su dirección personal, lo que nos habla de su carácter accesible y de su actitud de puertas abiertas para todo el que necesitara sus servicios.

Un hombre con las características del doctor Calderón no podía permanecer indiferente ante el dolor de cientos de compatriotas que, en medio del hambre y de la pobreza, carecían de medios para atender sus necesidades básicas. Él sabía que más allá de los pacientes que podía curar directamente, existían otros que no tenían acceso a medicinas ni a atención médica, y su sueño fue crear las condiciones para curarlos a todos.

Como lo afirmó en el mensaje inaugural al Congreso Constitucional el 8 de mayo de 1940, él necesitaba: "Amparar a la madre, defender la vida que nace, prevenir enfermedades, consolar decrepitudes, mantener vivo el sentimiento de fraternidad por el estricto acatamiento de los dictados de la justicia y los mandatos de la benevolencia; es faena sagrada que desde el Poder impulsaré con todas las fuerzas de mi espíritu."

En ese discurso inaugural, su pensamiento reflejaba ya lo que sería el hito más importante de la medicina costarricense, su obra magna: la creación de la Caja Costarricense de Seguro Social, así como también otros logros para la sociedad costarricense, como fueron la creación de la Universidad de Costa Rica y el Capítulo de las Garantías Sociales con el Código del Trabajo.

Es claro que su pensamiento médico, expresado desde la campaña electoral y luego en el discurso inaugural, reflejaban claramente cuál iba a ser el rumbo que tomaría su administración.

Con la creación de la CCSS el 1 de noviembre de 1941, empezó la verdadera revolución de la medicina costarricense, hasta llegar a lo que hoy tenemos: una Seguridad Social sólida, solidaria y con cobertura universal, sistema médico que es ejemplo en el mundo.

Se puede afirmar con certeza que una de las decisiones más trascendentales del doctor Calderón Guardia fue la creación de la CCSS, indudablemente el acto más importante que médico alguno haya realizado por la salud de los costarricenses, siendo esta una de las razones más importantes para que fuera declarado Benemérito de la Patria el 17 de abril de 1974, honor que comparte junto con su padre, el Dr. Rafael Calderón Muñoz, también Benemérito de la Patria.

El Dr. Rafael Angel Calderón Guardia falleció en San José el 9 de junio de 1970, en el mismo Hospital en donde ejerció con esmero su profesión: el Hospital San Juan de Dios.

Elías Jiménez-Fonseca

Pediatra Hematólogo, Hospital CIMA-San José 